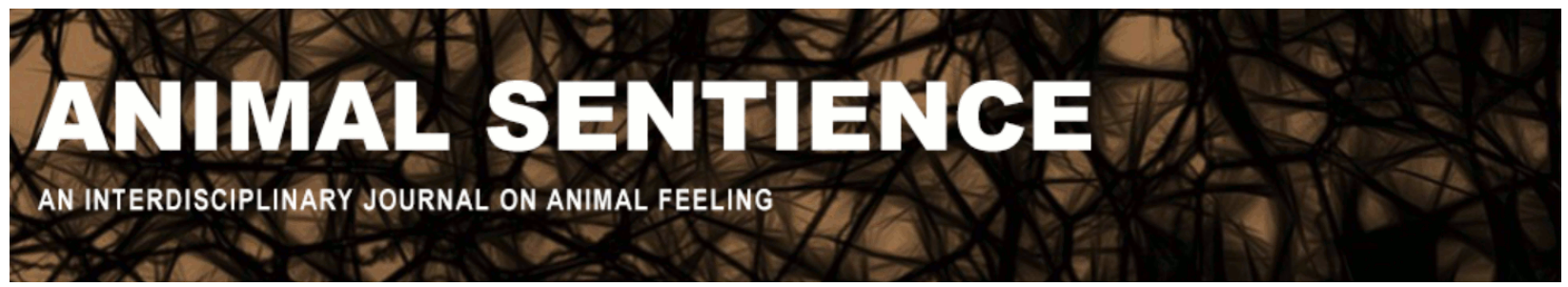

Franklin, Robert G., Jr. (2017) Canine emotions and the bond between humans and dogs. Animal Sentience 14(6)

DOI: $10.51291 / 2377-7478.1240$

Date of submission: 2017-11-01

Date of acceptance: 2017-11-06

(c)

This article has appeared in the journal Animal

Sentience, a peer-reviewed journal on animal

cognition and feeling. It has been made open access,

free for all, by WellBeing International and deposited

in the WBI Studies Repository. For more information,

please contact

wbisr-info@wellbeingintl.org.

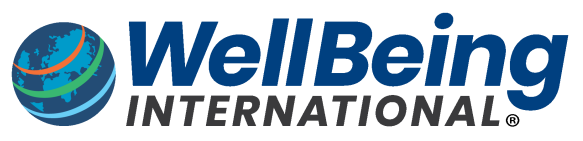

SOLUTIONS FOR PEOPLE, ANIMALS AND ENVIRONMENT 


\title{
Canine emotions and the bond between humans and dogs
}

\author{
Commentary on Kujala on Canine Emotions
}

Robert G. Franklin, Jr.

Department of Behavioral Sciences

Anderson University

\begin{abstract}
I explore how the findings reviewed by Kujala (2017) influence our understanding of the human-dog bond. The special social cognitive abilities of dogs may be unique among animal species, probably influenced by the circumstances surrounding canine domestication. The bond has influenced animal welfare policies, giving dogs a privileged place among animals. To determine what protections other species should have in a rational animal welfare policy, more research is needed on whether other species have similar social cognitive abilities.
\end{abstract}

Robert Franklin is Assistant Professor of Psychology at Anderson University, South Carolina. His research interests include examining how humans extend empathy to non-human entities, especially dogs, and how empathy for animals influences social policy.

https://www.andersonuniversity.edu/artssciences/faculty/robert-franklin

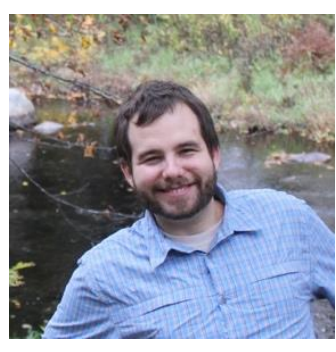

Is the human-dog relationship unique? Kujala (2017) reviews a growing behavioral and neuroscientific literature on dogs' emotional experience and social and cognitive abilities. I will focus on how these findings illuminate human-canine relationships. Is the human-dog bond unique among all human-animal relationships? If so, why is it so influential?

Humans readily attribute human-like emotional states to dogs. As Kujala notes, even Darwin assumed human-like emotional ability in dogs, never questioning the "communication and empathy between him and his dog" (see Buck \& Ginsberg, 1997).

The special place humans reserve for dogs may be due to the unique combination of warmth and competence humans perceive in them. Sevillano and Fiske (2016) applied the Stereotype Content Model to animals, examining how humans perceive various species of animals in terms of warmth and competence. Dogs were seen as the most competent species, often characterized as "intelligent" and "skillful," although their mean rated competence was not much higher than that of monkeys. Dogs were also rated more highly than any other species in warmth ("well-intentioned," "friendly"). Their mean rating of 8.07 in warmth on a 9-point scale was almost a full standard deviation above that of the next highest rated species: cats.

Why are dogs rated so highly on these scales? One possibility is cuteness. However, many other species are seen as equally cute. Another possibility is that that dogs are perceived as the smartest species. Sevillano and Fiske (2016) found that dogs were rated as the most competent species, but in another study (Zebrowitz et al., 2011) foxes were rated as "shrewder" than dogs. 
Objective studies of neural function have found that cetaceans and primates have cognitive capacities equal to or surpassing those of canines (Roth \& Dicke, 2005).

The special bond between humans and dogs is due to canine emotional abilities. The findings reviewed by Kujala suggest another potential reason the human-dog bond is special: dogs and humans may share social cognitive abilities that are unique among animal species. Dogs show human-like gaze patterns and have activation in face-specific brain areas when viewing human faces. They also have an impressive ability to read human emotional states and respond appropriately. Dogs act submissively in anticipation of human punishment - behaviors similar to guilt. They exhibit prosocial behavior, jealousy-like behavior in the face of unfair treatment, longterm emotional states, and emotional contagion.

That dogs are able to comprehend and respond appropriately to human emotions is probably a factor in why humans perceive them so favorably. As Kujala notes in Section 14, canine evolution was probably shaped by their social relationships with early humans. This may have depended on dogs' ability to read human mental states and to evoke empathetic human responses. This bond is unique among species; most examples of domestication are based on humans using animals for food or labor rather than on social relationships between animals and humans (Driscoll et al., 2009).

How does empathy for the suffering of dogs relate to a rational animal welfare policy? The human-canine emotional relationship has implications for animal welfare and environmental policy, including the question of animal suffering in food production. What people believe about social cognition in animals plays an important influence in how they feel they should treat them.

Humans relate very strongly to dog suffering, at least in Western culture. Franklin et al. (2013) found that American participants viewing dog suffering had brain activity patterns similar to those evoked by human suffering, unlike the activity patterns Filippi et al. (2010) found with images of animal suffering in the food industry. Neural activation in the anterior insula is even greater for canine than human suffering.

These pronounced human responses to dog suffering may explain why people find it so much more disturbing than the suffering of other animals. Europeans and Americans eat a variety of animals, but eating dogs is taboo in Western European, American, and Islamic cultures, and is becoming increasingly unpopular in China and Vietnam (Rosen, 2014). Hunters who use dogs to capture and kill other animals show compassion for their dogs but not for their prey. Author and hunter Aldo Leopold (1970) singled out the development of cooperation between dog and hunter as one of the primary joys of hunting.

Legal policies affecting animal welfare also prescribe treatment for dogs that does not extend to other species that may have similar social cognitive abilities. Dogs have some of the strongest legal protections in the European Union and United States; instances of dog abuse have become major media scandals. In contrast, crows show remarkable social cognitive abilities: they too can recognize human faces and respond to human social cues (Marzluff et al., 2010), yet hunting crows is rarely outlawed in the U.K. and U.S., and is even encouraged in some places with bounties.

Our policies for protecting animals should take into consideration the cognitive nature of the animals rather than just being based on whether the animal is cute, tasty, or a nuisance. The 
kind of research reviewed by Kujala needs to be extended to other species so we can adopt fair, rational and humane policies on animal welfare and animal rights, grounded in their cognitive capacities and needs. [See also Marino (2017) and Woodruff (2017), this journal - ed.]

Acknowledgement: The author acknowledges the contributions of the Labrador retriever Remi, whose unquestioned intelligence and social cognitive abilities inspired many of the arguments contained here.

\section{References}

Buck, R., \& Ginsburg, B. (1997). Communicative genes and the evolution of empathy. Annals of the New York Academy of Sciences, 807(1), 481-483.

Driscoll, C. A., Macdonald, D. W., \& O'Brien, S. J. (2009). From wild animals to domestic pets, an evolutionary view of domestication. Proceedings of the National Academy of Sciences, 106(Supplement 1), 9971-9978.

Filippi, M., Riccitelli, G., Falini, A., Di Salle, F., Vuilleumier, P., Comi, G., \& Rocca, M. A. (2010). The brain functional networks associated to human and animal suffering differ among omnivores, vegetarians and vegans. PLoS One, 5(5), e10847.

Franklin, Jr., R. G., Nelson, A. J., Baker, M., Beeney, J. E., Vescio, T. K., Lenz-Watson, A., \& Adams, Jr., R. B. (2013). Neural responses to perceiving suffering in humans and animals. Social Neuroscience, 8(3), 217-227.

Kujala, M. V. (2017). Canine emotions as seen through human social cognition. Animal Sentience 14(1).

Leopold, A. (1970). A Sand County Almanac: With Other Essays on Conservation from Round River. Random House Digital, Inc.

Marino, L. (2017). The inconvenient truth about thinking chickens. Animal Sentience 17(1).

Marzluff, J. M., Walls, J., Cornell, H. N., Withey, J. C., \& Craig, D. P. (2010). Lasting recognition of threatening people by wild American crows. Animal Behaviour, 79(3), 699-707.

Rosen, E. (2014). "To eat dog, or not to eat dog". The Atlantic. Retrieved November 2, 2017. Roth, G., \& Dicke, U. (2005). Evolution of the brain and intelligence. Trends in Cognitive Sciences, 9, 250-257.

Sevillano, V., \& Fiske, S. T. (2016). Warmth and competence in animals. Journal of Applied Social Psychology, 46(5), 276-293.

Woodruff, M. L. (2017). Consciousness in teleosts: There is something it feels like to be a fish. Animal Sentience 13(1).

Zebrowitz, L. A., Wadlinger, H. A., Luevano, V. X., White, B. M., Xing, C., \& Zhang, Y. (2011). Animal analogies in first impressions of faces. Social cognition, 29(4), 486-496. 


\section{ANIMAL CONSCIOUSNESS}

On November 17-18, 2017, the NYU Center for Mind, Brain and Consciousness, the NYU Center for Bioethics, and NYU Animal Studies will host a conference on Animal Consciousness.

This conference will bring together philosophers and scientists to discuss questions such as: Are invertebrates conscious? Do fish feel pain? Are nonhuman mammals self-conscious? How did consciousness evolve? How does research on animal consciousness affect the ethical treatment of animals? What is the impact of issues about animal consciousness on theories of consciousness and vice versa? What are the best methods for assessing consciousness in nonhuman animals?

\section{Speakers and panelists include:}

Colin Allen (University of Pittsburgh, Department of History \& Philosophy of Science), Andrew Barron (Macquarie, Cognitive Neuroethology), Victoria Braithwaite (Penn State, Biology), Peter Carruthers (Maryland, Philosophy), Marian Dawkins (Oxford, Zoology), Dan Dennett (Tufts, Philosophy), David Edelman (San Diego, Neuroscience),

Todd Feinberg (Mt. Sinai, Neurology), Peter Godfey-Smith (Sydney, Philosophy), Lori Gruen (Wesleyan, Philosophy), Brian Hare (Duke, Evolutionary Anthropology), Stevan Harnad (Montreal, Cognitive Science), Eva Jablonka (Tel Aviv, Cohn Institute), Björn Merker (Neuroscience), Diana Reiss (Hunter,

Psychology), Peter Singer (Princeton, Philosophy), Michael Tye (Texas, Philosophy)

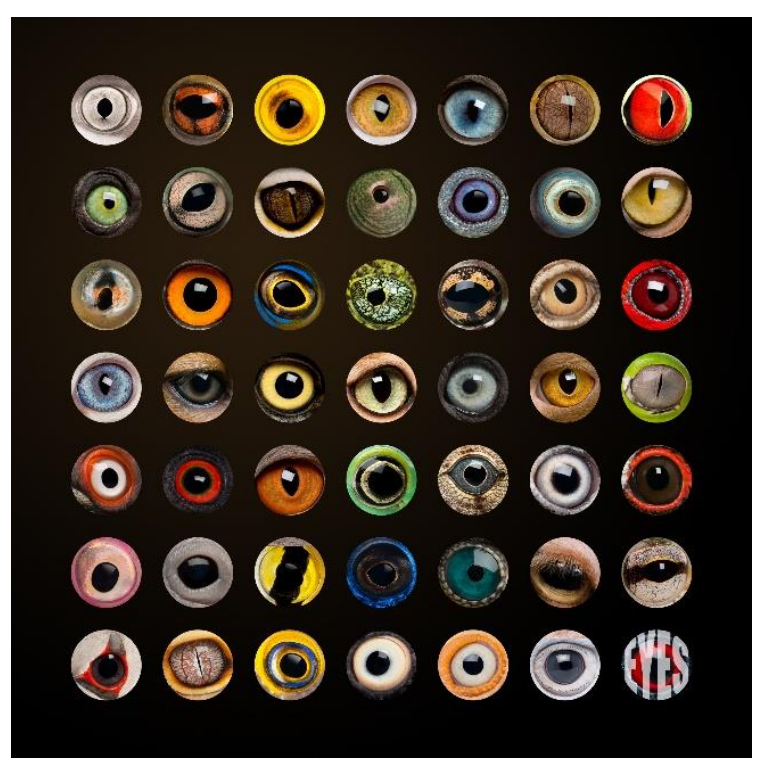

Organizers: Ned Block, David Chalmers, Dale Jamieson, S. Matthew Liao.

The conference will run from 9am on Friday November 17 to $6 \mathrm{pm}$ on Saturday November 18 at the NYU Cantor Film Center (36 E 8th St).

Friday sessions will include "Invertebrates and the evolution of consciousness", "Do fish feel pain?", and "Animal consciousness and ethics".

Saturday sessions will include "Animal self-consciousness", "Animal consciousness and theories of consciousness", and a panel discussion.

A detailed schedule will be circulated closer to the conference date.

Registration is free but required.

\section{Register here.}

\section{See also the conference website}

